
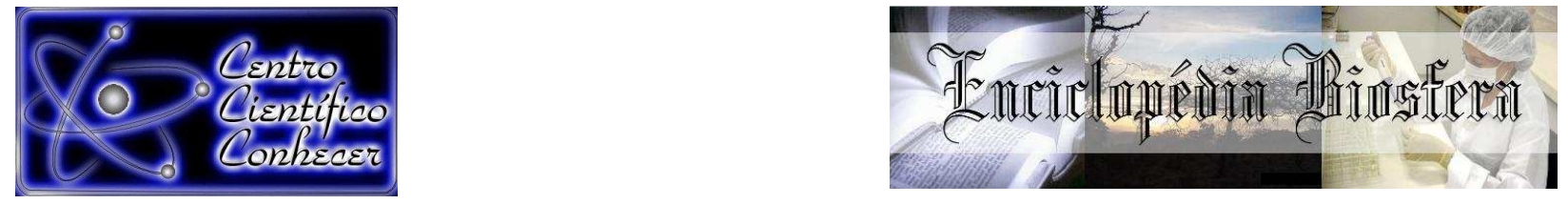

\title{
PROPOSTA DE ELABORAÇÃO DE CORREDORES ECOLÓGICOS PARA BACIA DO RIO CAIÇA, BA/SE
}

Myla Rebeca Andrade dos Santos ${ }^{1}$, Ivane Marcley Nascimento Sena ${ }^{1}$, Lucas dos $\underline{\text { Santos Batista }}{ }^{1}$

${ }^{1}$ Mestrandos em Recursos Hídricos pela Universidade Federal de Sergipe (lucasbaptistaufrb@gmail.com).

Recebido em: 03/10/2016 - Aprovado em: 21/11/2016 - Publicado em: 05/12/2016 DOI: 10.18677/EnciBio_2016B_082

\begin{abstract}
RESUMO
A bacia hidrográfica do rio Caiçá engloba uma porção dos estados da Bahia e Sergipe. Possui uma extensão de aproximadamente $170,47 \mathrm{~km}^{2}$, que tem perdido significativa parte da vegetação existente para atividade antrópica. Atualmente, existem apenas fragmentos de vegetação nativa, principalmente, em esferas destinadas a pecuária e agricultura. Sendo assim, este trabalho objetiva a elaboração de propostas dos corredores ecológicos para ligar esses fragmentos propiciando a interação entre os mesmos. Procedeu-se para tal, com a identificação dos usos e ocupações do solo na referida bacia para identificar as extensões de vegetação significativas. Concluiu-se, então, que unir todos os fragmentos de vegetação em um corredor seria inviável, propondo-se que fossem criados corredores que unissem as áreas A1-A2, A2-A3, A1-A3 e A4-A5 com elevadas chances de êxitos para migração de espécies entre essas áreas, minimizando os riscos de extinção das mesmas.
\end{abstract}

PALAVRAS-CHAVE: Interação, Ocupação.Vegetação.

\section{PROPOSAL FOR DEVELOPMENT OF ECOLOGICAL CORRIDORS FOR THE RIVER BASIN CAIÇA BA/SE}

\begin{abstract}
The watershed of the rio Caiçá encompasses a portion of the states of Bahia and Sergipe. It has an area of approximately $170.47 \mathrm{~km}^{2}$, which has lost significant part of the existing vegetation to anthropogenic activity. Currently, there are only fragments of native vegetation, mainly in areas intended for livestock and agriculture. Thus, this work aims to draw up proposals for ecological corridors to connect these fragments, facilitating the interaction between them. Had to do this, with the identification of uses and occupations of the soil in that basin to identify areas of significant vegetation. It is concluded, then, that a runner which unites all the fragments of vegetation would be unfeasible, suggesting that they were created corridors that join the areas A1-A2, A2A3, A1-A3 and A4-A5 with high chances of success for migration of species between these areas, minimizing the risk of extinction of same.
\end{abstract}

KEYWORDS: Vegetation, Interaction, Occupation. 


\section{INTRODUÇÃO}

Os biomas brasileiros vêm sofrendo drásticas alterações, sendo a redução e fragmentação dos habitats naturais as mais acentuadas modificações causadas pela ação antrópica no meio ambiente (CARNEIRO et al., 2013). Para PEREIRA et al., (2007), a fragmentação territorial trata da divisão de uma mancha do habitat em partes pequenas, incluindo a transformação e destruição do habitat.

Buscando preservar os ecossistemas existentes, a legislação brasileira assegura que sejam criados elementos de conservação destinados à proteção e conservação desses. Contudo, uma das maiores dificuldades enfrentadas em parques e reservas é o crescente isolamento dessas regiões. A exacerbada exploração antrópica do uso e ocupação do solo aumenta este isolamento (SEOANE et al., 2010) que pode acarretar em sérias complicações para o ecossistema como um todo, uma vez que populações isoladas são mais suscetíveis a eventos demográficos e ambientais aleatórios, tornando-as mais vulneráveis à fenômenos de extinção (AYRES et al., 2005).

A interação entre diferentes populações se torna necessária para manter a diversidade genética entre as espécies. A existência de zonas protegidas, interligadas, quando possível, por meio de corredores ecológicos, é uma maneira de minimizar esses processos de degradação e assegurar a proteção de espécies e ecossistemas (CARNEIRO, 2013). A criação desses corredores é uma tentativa de desfragmentar a paisagem e permitir o movimento dos indivíduos, nutrientes e energia entre habitats isolados (ANDERSON \& JENKINS, 2007) evitando o isolamento destas zonas de proteção.

Embora os corredores sejam implantados com a suposição de que irão aumentar a biodiversidade, não há pesquisas suficientes que comprovem isso. Essas unidades ecológicas têm sido construídas mais na intuição que em evidência empírica (TEWKSBURY et al., 2002). Baseado nessa premissa, esta é uma técnica com grandes chances de sucesso, comprovada na literatura por inúmeras paisagens experimentais, que foram capazes de integrar a investigação sobre a fragmentação e conectividade através de interações planta-animal, fornecendo quadros de previsão para determinar os tipos de plantas que respondem a essa conectividade (ROCHA et al., 2006).

No Brasil, o conceito de Corredores ecológicos ou Corredores de Biodiversidade é relativamente novo; essa estratégia de conservação vem sendo construída dentro do Ministério de Meio Ambiente desde 1997, no âmbito do Programa Piloto para Proteção das Florestas Tropicais no Brasil (AYRES et al., 2005). Que lida com a dinâmica da fragmentação e promove a formação e a conservação de grandes corredores na Amazônia e na Mata Atlântica.

Para ROCHA et al. (2006), os corredores ecológicos são elementos capazes de manter e/ou estabelecer a conectividade em paisagem fragmentada, tornando-a mais permeável, favorecendo a movimentação e a recolonização e diminuindo o risco de extinção das espécies. Segundo BRASIL (2015), os corredores ecológicos são extensões que contêm ecossistemas florestais prioritariamente biológicos e possível a conservação da biodiversidade, objetivando manter ou restaurar a conectividade da paisagem e facilitar o fluxo genético entre populações, ampliando, assim, as chances de sobrevivência das comunidades biológicas.

Neste sentido, o objetivo desse estudo é propor a criação de um corredor ecológico na bacia do rio Caiçá, em uma tentativa de desfragmentar áreas de proteção objetivando sua reestruturação, conservação tanto da fauna como da flora, 
evitando, assim, eventos de extinção de espécies, além de proporcionar a preservação do meio ambiente e melhor condição de vida do ser humano.

\section{MATERIAL E MÉTODOS}

\section{Área de estudo}

O presente estudo foi desenvolvido na bacia do rio Caiçá, Figura 1, que engloba as regiões dos estados de Bahia e Sergipe. A porção sergipana, compreende os municípios de Simão Dias e Lagarto e, no território baiano, o município de Paripiranga. Atualmente, só é possível encontrar fragmentos isolados da vegetação que outrora existia na região e deu espaço, principalmente, a agricultura e pecuária. A região ainda sofre com a interferência do adensamento populacional no município de Simão Dias, que fica no interior do estado de Sergipe.

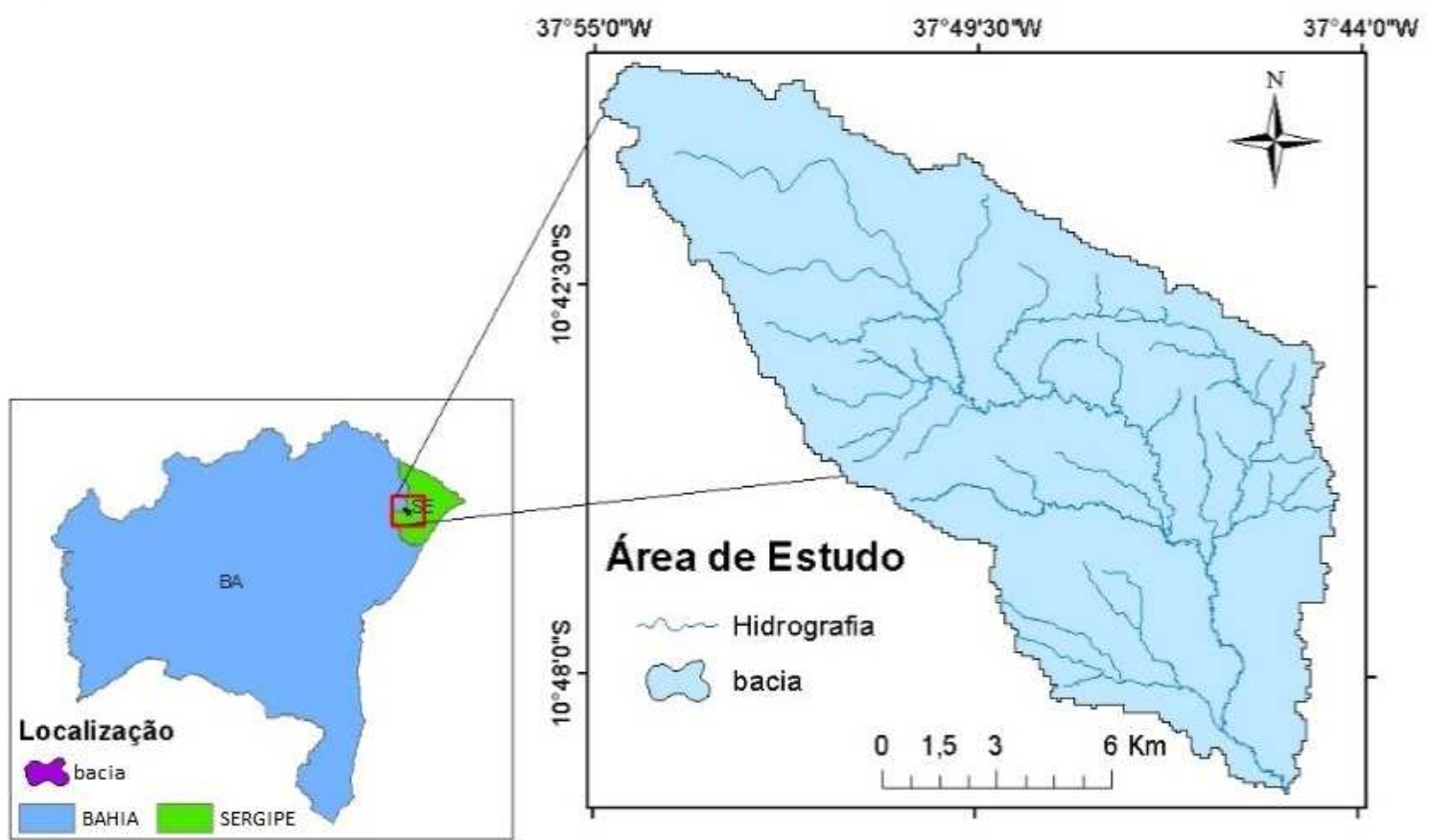

FIGURA 1. Bacia hidrográfica do rio Caiçá situada entre os estados da Bahia e Sergipe.

A bacia do rio Caiçá compreende uma extensão de aproximadamente170,47 $\mathrm{km}^{2}$. A Figura 2 demonstra de forma mais detalhada o uso e ocupação do solo na bacia do rio Caiçá. Verifica-se que a maior porção da bacia, cerca de $71 \%$, é destinada para pastagem, seguida por $14 \%$ de áreas agrícolas. A atribuição de espaços para essas atividades foi possível mediante o desmatamento da vegetação existente, restando apenas $13 \%$ da área total da bacia com vegetação nativa. 


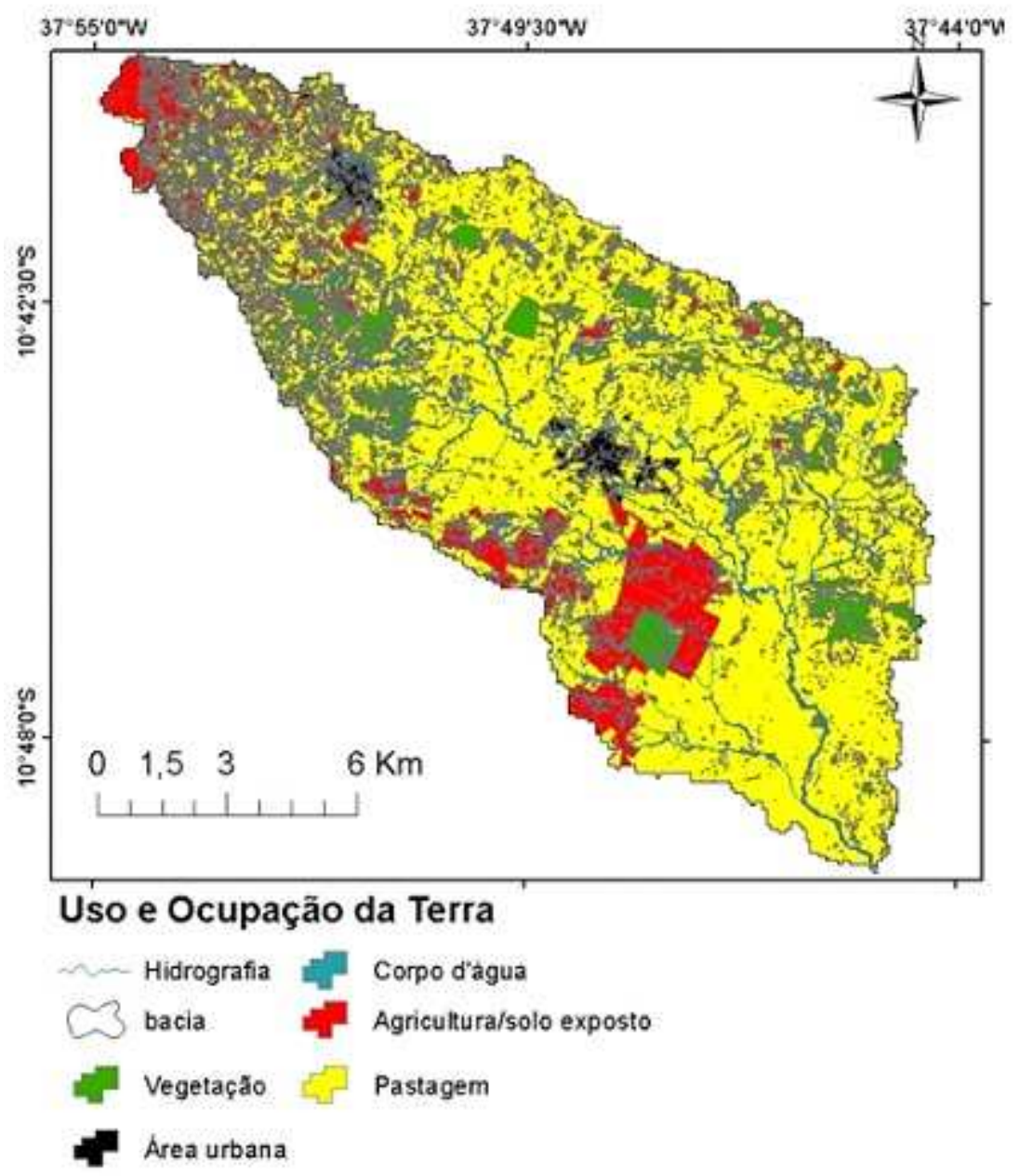

FIGURA 2. Uso e ocupação do solo na bacia do rio Caiçá.

\section{Geração do Corredor}

Para elaboração do corredor, identificou-se os fragmentos de vegetação nativa ao longo da bacia a partir do mapa de uso e ocupação do solo gerado por vetorização de imagem manual, diretamente pelo computador, com auxílio de um Sistema de Informação Geográfica (SIG) datada de 10 de dezembro de 2013. A imagem, com referência espacial Datum WGS 1984 UTM Zona 24S, foi fornecida pelo Ministério do Meio Ambiente (MMA).

Foram identificadas 5 áreas de vegetação preservada. A Tabela 4 apresenta as áreas dessas regiões vegetadas e consideradas para construção do corredor. $O$ fato dessas zonas terem formato compacto, melhoram as chances de êxito na preservação do ecossistema uma vez que sofrem menos impacto do meio externo quando comparado aos fragmentos mais alongados.

TABELA 1. Áreas das regiões vegetadas a serem ligadas por corredores.

\begin{tabular}{lc}
\hline Vegetação & Área (ha) \\
\hline A1 & 0,38 \\
A2 & 1,04 \\
A3 & 0,75 \\
A4 & 1,02 \\
A5 & 1,36 \\
\hline
\end{tabular}


Para elaboração do corredor ecológico, foi necessária a elaboração de mapas de custo do uso e ocupação, da declividade e de APP. Considerou-se como APP uma extensão de 30 metros ao longo da margem do rio Caiçá e com 50 metros de raio ao longo da nascente do mesmo. Regiões que apresentam declividade igual ou superior a 45ำ também são consideradas como APP, porém, para a bacia estudada, a maior declividade encontrada foi de $24^{\circ}$.

Cada classe do mapa de custo gerado teve um peso atribuído, variando de 1 a 100, sendo o menor representado pela área mais adequada para a criação do corredor. Esses pesos podem ser observados das Tabelas 2, 3 e 4.

TABELA 2. Custos atribuídos as classes de uso.

\begin{tabular}{lc}
\hline Uso & Custo atribuído \\
\hline Área edificada & 100 \\
Agricultura/solo exposto & 100 \\
Pastagem & 50 \\
Corpo d'água & 1 \\
Vegetação & 1 \\
\hline
\end{tabular}

TABELA 3. Custos atribuídos às classes de declividade.

\begin{tabular}{lc}
\hline Declividade & Custo atribuído \\
\hline$<20$ & 100 \\
20 a 45 & 50 \\
\hline
\end{tabular}

TABELA 4. Custos atribuídos às classes de APP.

\begin{tabular}{lc} 
APP & Custo atribuído \\
\hline Inexistente & 1 \\
Existente & 100 \\
\hline
\end{tabular}

O custo total, expressado através da Equação 1, foi realizado utilizando-se o método de Analytic Hierarchy Process - AHP, proposto por SAATY (1977), com o objetivo de encontrar os pesos estatísticos para cada mapa de custo individual. Para obtenção dos respectivos pesos se fez necessário classificar previamente cada mapa por grau de importância (Tabela 5).

Custo Total $=\left(P_{1} *\right.$ Custo Delividade $\left._{\text {De }}\right)+\left(P_{2} *\right.$ Custo $\left._{\text {App }}\right)+\left(P_{3} *\right.$ Custo $\left._{\text {Uso }}\right)($ Eq. 1$)$

TABELA 5. Matriz de comparação de importância.

\begin{tabular}{cccc}
\hline Fatores & Declividade & APPs & Uso \\
\hline Declividade & 1 & 0,33 & 0,2 \\
APPs & 3 & 1 & 0,33 \\
Uso & 5 & 3 & 1 \\
\hline
\end{tabular}

A partir do mapa de custo total, foi possível obter os mapas de distância e direção, os quais serviram de base para criação dos corredores que liga as áreas de vegetação nativa. $O$ primeiro corredor liga a região $A 1$ a região $A 2$ (corredor $A 1-A 2$ ), o segundo une as áreas A2 a A3 (corredor A2-A3), o terceiro corredor proposto liga 
as áreas A3 a A4 (corredor A3-A4), o quarto conecta a região A4 a A5 (corredor A4A5) e o quinto corredor liga as áreas A5 a A1 (corredor A5-A1).

A largura do corredor ecológico utilizada neste trabalho seguiu a Resolução n. 9 de 1996 do CONAMA, que determina que a mesma seja correspondente a $10 \%$ do comprimento do corredor. A metodologia utilizada foi de acordo a LOUZADA et al. (2012) e pode ser observada a partir do fluxograma representado pela Figura 6.

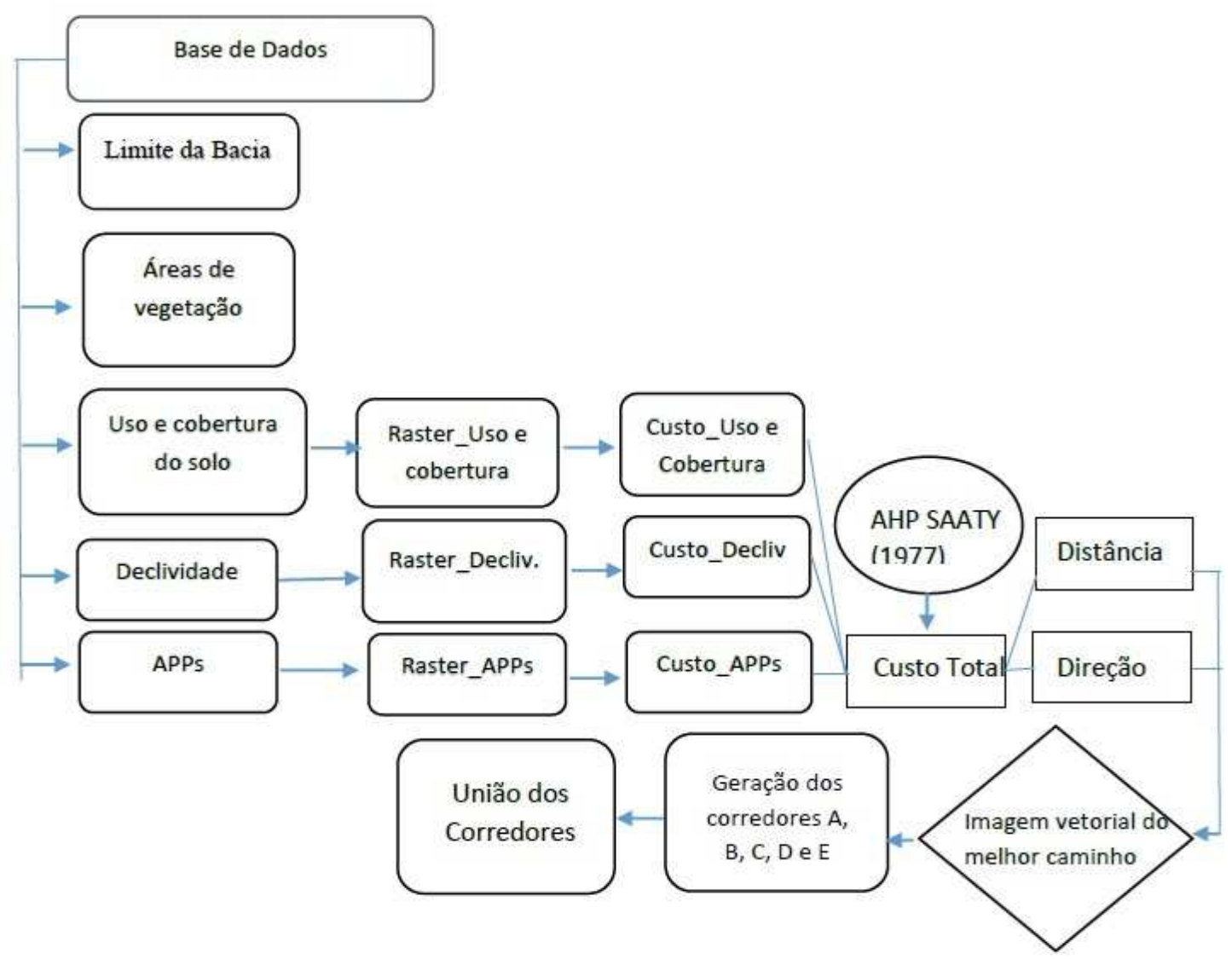

FIGURA 3. Fluxograma da geração da proposta de corredores ecológicos.

\section{RESULTADOS E DISCUSSÃO}

A bacia do rio Caiçá teve significativa parte da vegetação nativa desmatada pela atividade antrópica e atualmente, há apenas fragmentos da vegetação nativa. As áreas de vegetação preservadas estão dispostas na bacia de forma fragmentada, fato que tem prejudicado a preservação dos ecossistemas, visto que, os mesmos ficam isolados e, consequentemente, expostos a eventos de extinção. A existência de aglomeração urbana, em área correspondente a $2 \%$ do total da bacia, eleva ainda mais o impacto a que esses ecossistemas estão submetidos.

Os fragmentos de vegetação existentes na bacia estão cercados por pastagem e áreas agrícolas, com a área urbana localizada entre esses fragmentos e próxima ao curso d'agua do rio Caiçá. Fato que, inclusive, tem prejudicado a característica da água do referido rio devido à ausência de um adequado monitoramento e gestão desse recurso. O rio Caiçá é um importante corpo d'água na região, sendo classificado como um curso d'água de ordem 4, conforme 0 sistema de drenagem, seguindo a hierarquia de Strahler. Ordem inferior ou igual a 4 é comum em pequenas bacias hidrográficas (FERRARI et al., 2012). 
Sendo assim, a criação de corredores ecológicos para ligar os fragmentos de vegetação torna-se de fundamental importância. A Figura 4 apresenta o custo total obtido para a bacia hidrográfica do rio Caiçá. Em vermelho, estão representadas as regiões inadequadas para criação de corredores, e em verde as áreas mais apropriadas para essa finalidade.

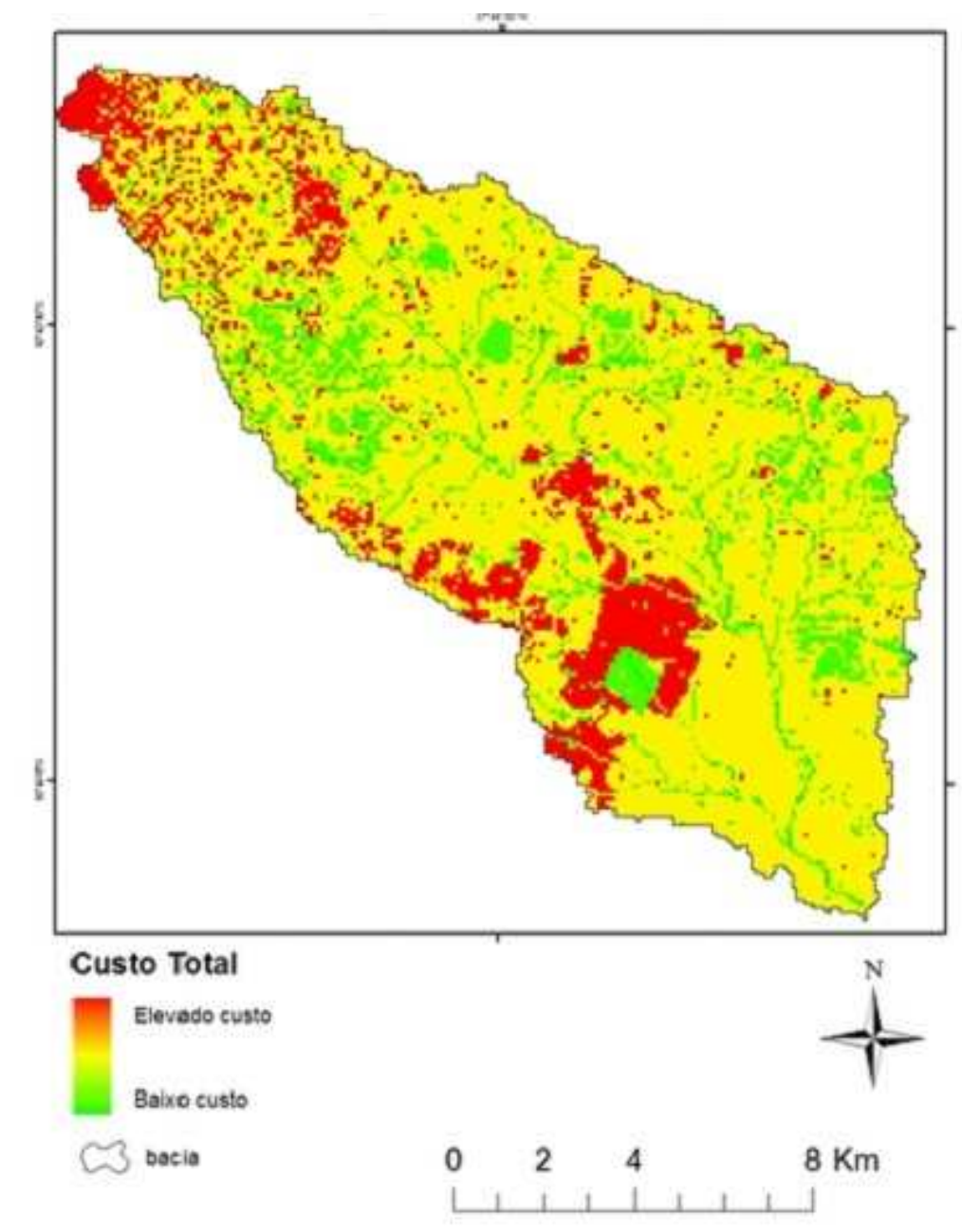

FIGURA 4. Custo total obtido para a bacia do rio Caiçá.

A bacia do rio Caiçá possui cinco fragmentos significativos de vegetação preservada que ficam dispostos em regiões que predominam a atividade de pastagem, seguida por agricultura. Para unir esses fragmentos, foram sugeridos cinco corredores, representados na Figura 5, que estão dispostos de forma isolada e unida em uma única proposta. 


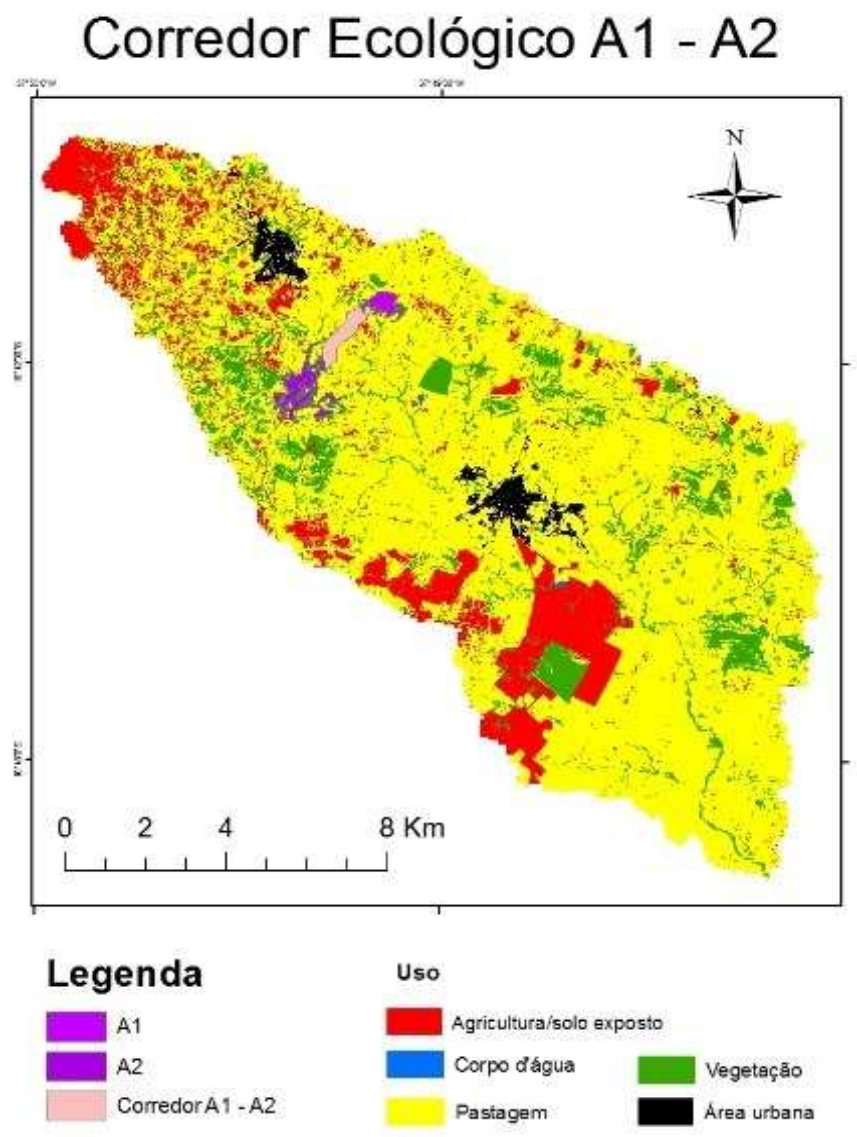

Corredor Ecológico A2 - A3
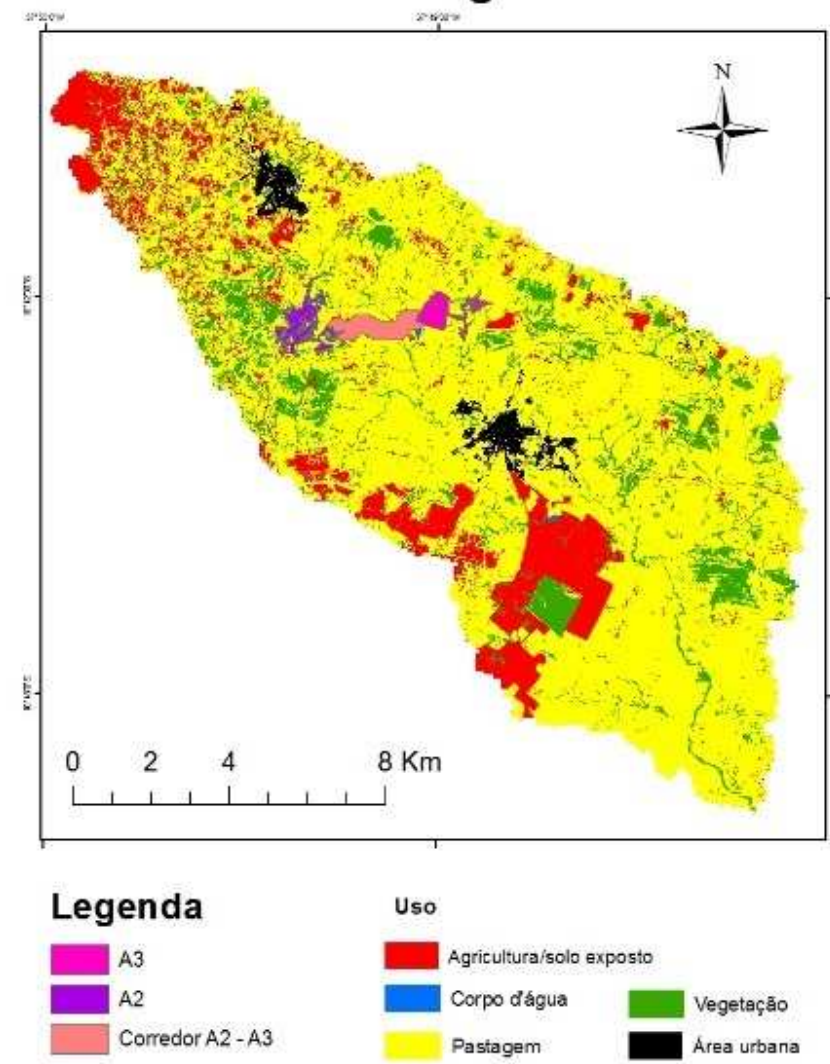


\section{Corredor Ecológico A3 - A4}

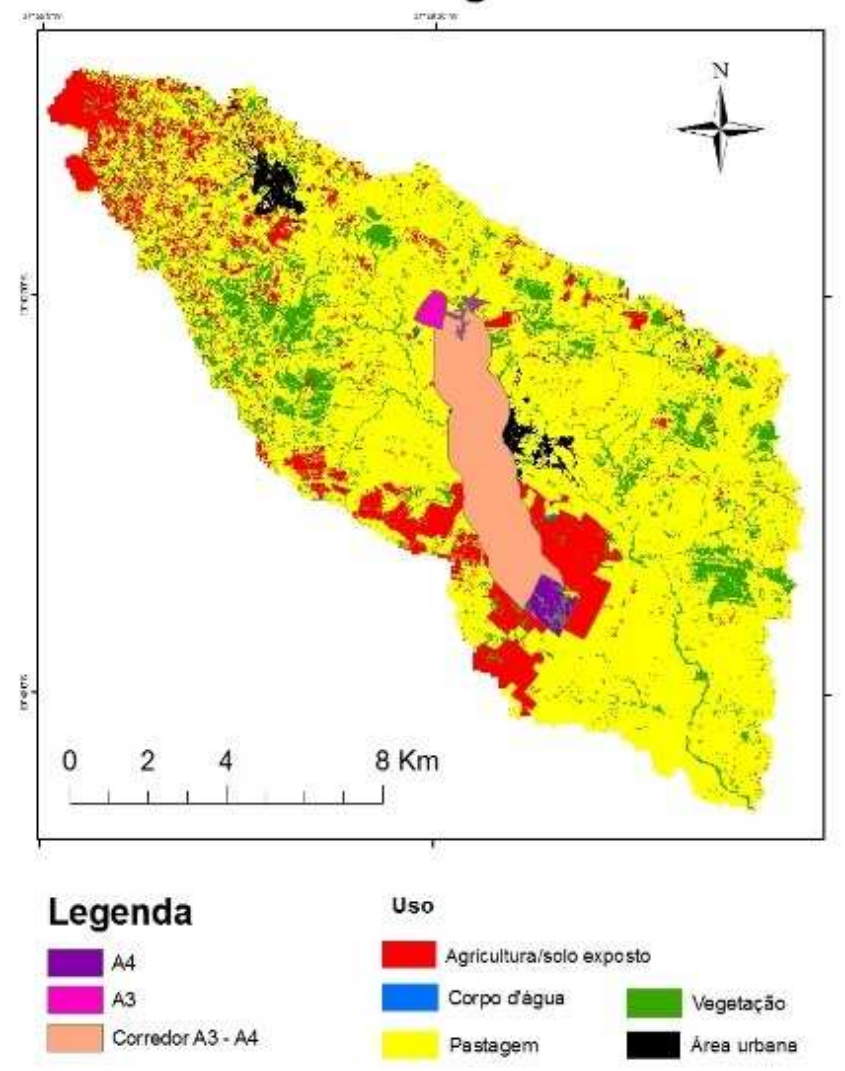

Corredor Ecológico A4 - A5

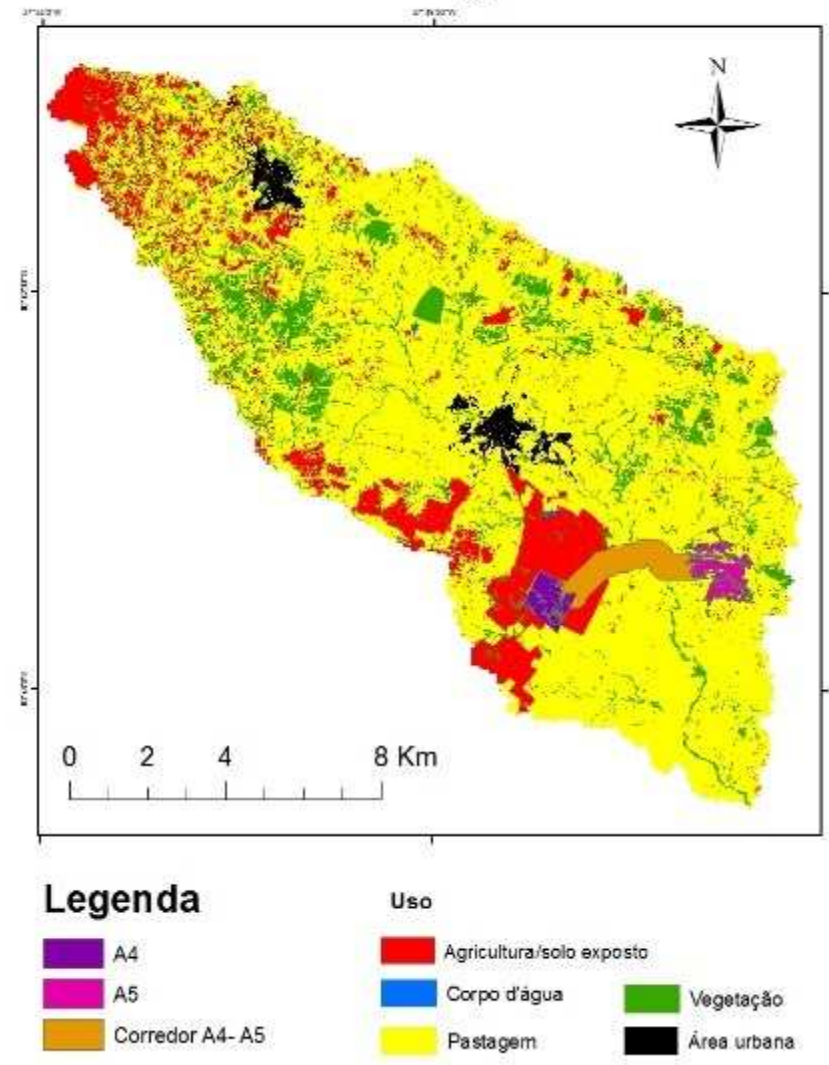




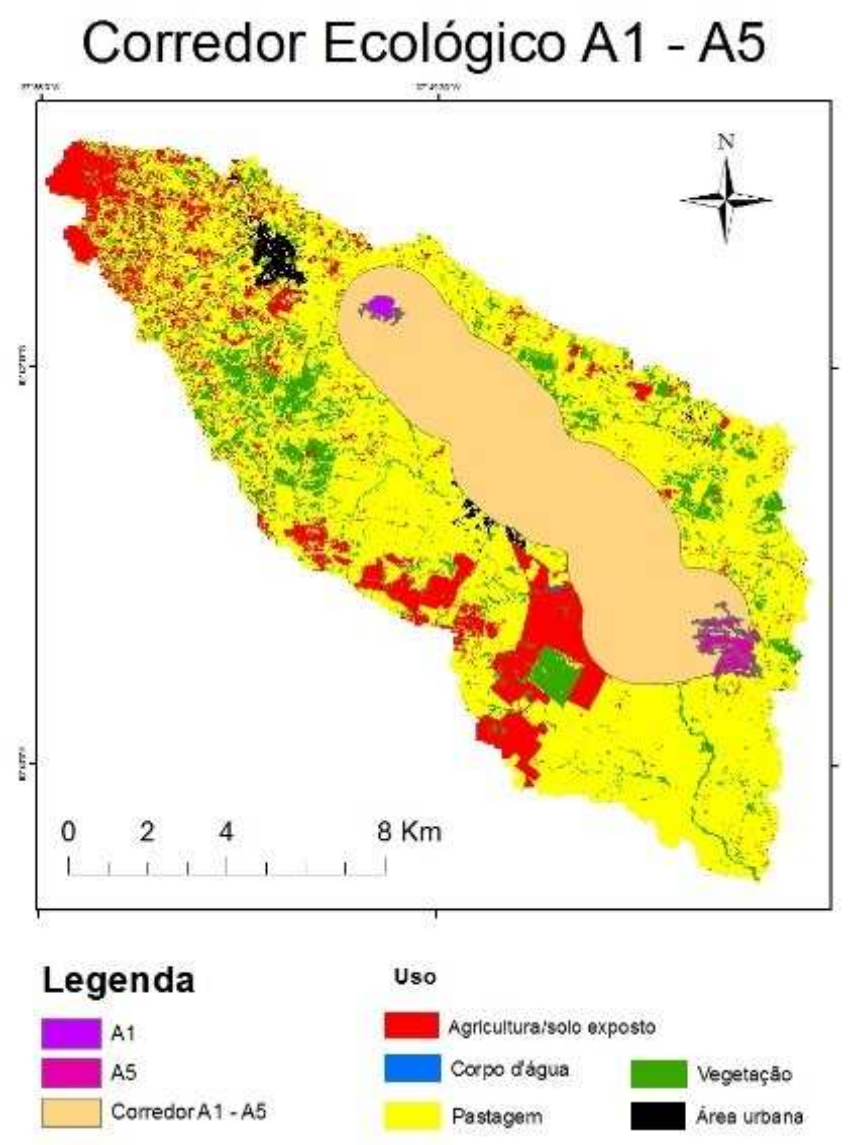

FIGURA 5. Proposta de corredores ecológicos para bacia do rio Caiçá.

Os corredores propostos atravessam, em maior parte, áreas de pastagem, por ser o uso dominante da bacia estudada. Na bacia é verificado um grande conflito de uso do solo em áreas que deveriam ser de APPs (Tabela 6), principalmente, áreas que foram derrubadas para dar lugar a pastagem. $\mathrm{O}$ aproveitamento dessas áreas antropizadas de forma ilegal poderiam facilitar o processo de criação dos corredores. Priorizar as áreas de APPs na elaboração do corredor ecológico, tornase atrativo, uma vez que a aplicação da legislação sobre as APPs pode favorecer a interligação de vários fragmentos florestais remanescentes da região, minimizando a ocorrência de possíveis problemas ambientais, bem como, a redução de possíveis custos no reflorestamento nativo (OLIVEIRA, 2013).

TABELA 6. Conflito do uso do solo em áreas de APP.

\begin{tabular}{lc}
\hline USO & $\%$ Total \\
\hline Agricultura/solo exposto & 0,161 \\
Área urbana & 0,014 \\
Corpo d'água & 0,0024 \\
Pastagem & 99,77 \\
Vegetação & 0,054 \\
Soma & 100 \\
\hline
\end{tabular}


Os corredores foram dispostos de forma que todas as áreas de vegetação significativas fossem ligadas umas às outras facilitando a migração de espécies e, por consequência, a sua preservação. Contudo, os corredores formam uma espécie de ilha que abrigam, entre outros usos da terra, uma aglomeração urbana, onde, seria necessária a abertura de caminhos para possibilitar a passagem de pessoas e automóveis.

Assim, a criação de todos esses corredores não seria viável. As tabelas abaixo, apresentam a porcentagem de uso existente na área destinada a criação dos corredores propostos. É possível verificar que grande parte da área a ser utilizada atualmente é destinada a pastagem. Muito pouco de área vegetada será aproveitada, variando entre os corredores de 1,23 a 4,24\% da área total do corredor. Os corredores A3-A4, A4-A5 e A5-A1 seriam os que atravessariam uma maior porcentagem de áreas agrícolas, variando de 5 a 6,24\% da área total do corredor. Os corredores A3-A4 e A5-A1 atravessariam área urbana, o que possivelmente acarretaria em maiores custos, inclusive, com desapropriação de imóveis.

TABELA 7. Porcentagem dos usos no corredor A1-A2.

\begin{tabular}{lcc}
\hline Uso & Área & Porcentagem \\
\hline Agricultura/solo exposto & 0,06 & 0,051 \\
Pastagem & 121,55 & 98,71 \\
Vegetação & 1,52 & 1,24 \\
Total Geral & 123,14 & 100 \\
\hline
\end{tabular}

TABELA 8. Porcentagem dos usos no corredor A2-A3.

\begin{tabular}{lcc}
\hline Uso & Área & Porcentagem \\
\hline Agricultura/solo exposto & 0,05 & 0,04 \\
Pastagem & 121,55 & 98,35 \\
Vegetação & 1,99 & 1,61 \\
Total Geral & 123,59 & 100 \\
\hline
\end{tabular}

TABELA 9. Porcentagem dos usos no corredor A3-A4.

\begin{tabular}{lcc}
\hline Uso & Área & Porcentagem \\
\hline Agricultura/solo exposto & 8,37 & 6,24 \\
Área urbana & 1,87 & 1,39 \\
Pastagem & 121,55 & 90,41 \\
Vegetação & 2,65 & 1,97 \\
Total Geral & 134,45 & 100 \\
\hline
\end{tabular}

TABELA 10. Porcentagem dos usos no corredor A4-A5.

\begin{tabular}{lcc}
\hline Uso & Área & Porcentagem \\
\hline Agricultura/solo exposto & 6,55 & 5,00 \\
Pastagem & 121,55 & 92,87 \\
Vegetação & 2,79 & 2,13 \\
Total Geral & 130,89 & 100 \\
\hline
\end{tabular}


TABELA 11. Porcentagem dos usos no corredor A5-A1.

\begin{tabular}{lcc}
\hline Uso & Área & Porcentagem \\
\hline Agricultura/solo exposto & 7,74 & 5,55 \\
Área urbana & 2,51 & 1,80 \\
Corpo d'água & 1,89 & 1,36 \\
Pastagem & 121,55 & 87,05 \\
Vegetação & 5,93 & 4,24 \\
Total Geral & 139,63 & 100 \\
\hline
\end{tabular}

Levando-se em consideração o comprimento do corredor proposto (Tabela 12), as áreas das vegetações que seriam ligadas, e os usos atuais das áreas por onde os corredores propostos passariam, a criação de um corredor que ligaria as áreas vegetadas A5-A1 não foi considerada viável, assim como, o corredor que liga as regiões A3-A4, já que atravessam áreas de agricultura e centros urbanos, formando um corredor extenso. Esse resultado mostra como a criação de corredores é controversa, uma vez que a sua eficácia pode variar muito entre os sistemas, dependendo da complexa interação entre o comportamento dispersor e da estrutura da paisagem.

Como alternativa para uma melhor interação entre espécies nas áreas $A 1, A 2$ e A3, propõe-se a criação do corredor que liga as áreas A1 e A3 como mostra a Figura 06. Contudo, seria necessário a construção de uma estrada ecológica para escoar a produção agrícola da atividade de pastagem existente na região, uma vez que a formação desses corredores isola a área que fica inserida dentro dos mesmos.

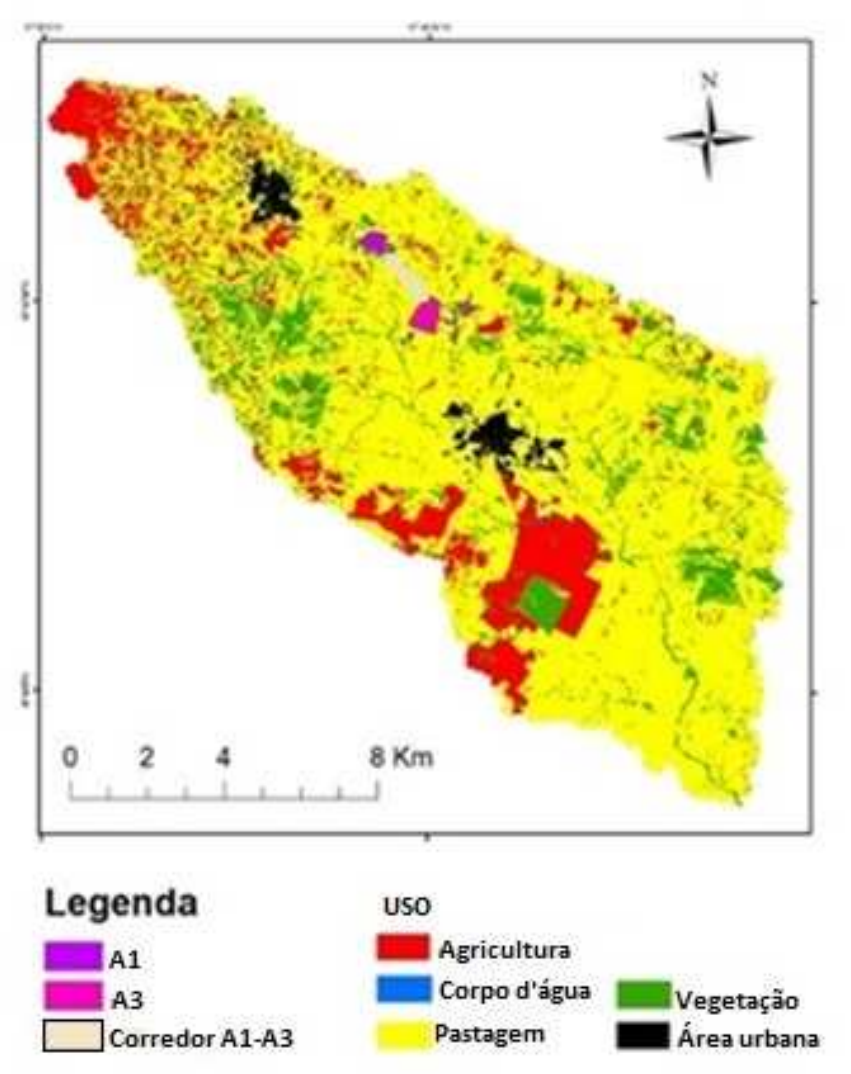

FIGURA 6. Corredor A1 à A3. 
TABELA 12. Dimensão dos corredores propostos.

\begin{tabular}{clll}
\hline Corredor & Comprimento $(\mathbf{m})$ & Largura $(\mathbf{m})$ & Buffer $(\mathbf{m})$ \\
\hline $\mathbf{1 - 2}$ & 3403,76 & 340,38 & 170,19 \\
$\mathbf{2 - 3}$ & 4679,84 & 467,98 & 233,99 \\
$\mathbf{3 - 4}$ & 13701,23 & 1370,12 & 685,06 \\
$\mathbf{4 - 5}$ & 6514,35 & 651,43 & 325,72 \\
$\mathbf{5 - 1}$ & 26762,80 & 2676,28 & 1338,14 \\
\hline
\end{tabular}

O corredor A4-A5 seria uma alternativa para a preservação da área vegetada A4, que fica cercada pela atividade agrícola, uma vez que é um corredor de um comprimento relativamente menor. Por atravessar uma região agrícola, aconselhase que seja utilizado nesse corredor o Sistema Agroflorestal, favorecendo o cultivo de plantas nativas e frutíferas. Para BRIENZA (2009), os sistemas agroflorestais (SAF's), quando utilizados como ecológicos corredores, objetivam conciliar a preservação da natureza e a prestação de serviços ambientais com a produção vegetal, possibilitando a geração de produtos agroflorestais de interesse dos produtores agrícolas.

CARDOSO \& AQUINO (2010), ao estudarem o uso e cobertura das terras da sub-bacia do riacho do Roncador em Timon no Maranhão, observaram que a classe vegetação nativa ocupa $70 \%$ da área da sub-bacia. Os valores encontrados relacionados a vegetação nativa se constitui, como de grande importância a qualidade e quantidade do volumes aos corpos d'água, já que as vegetações tropicais possuem a capacidade de conservar mineras essências devido à alta taxa de decomposição e fluxo de água. Segundo DEVIDE \& REBOUÇAS (2000), as matas conseguem reter cerca de $80 \%$ do fosforo e $89 \%$ do nitrogênio proveniente do escoamento superficial das áreas adjacentes, dependendo do desenvolvimento e tipo da vegetação como também do tipo de solo e relevo entre outros fatores.

Os corredores A1-A2 e A2-A3 apresentaram-se também como alternativas viáveis, inclusive, quando criados concomitantemente, uma vez que uniriam um maior número de espécies em uma área relativamente menor. Essas áreas de predominância de pastagem e a criação de corredores nessas regiões poderiam, inclusive, beneficiar essas atividades, uma vez, que sistemas silvipastoris são potencialmente mais sustentáveis que os sistemas tradicionais. Ou seja, os corredores A1-A2 e A2-A3, além de todos os benefícios que essa criação pode bonificar, trariam uma melhoria na atividade pecuária. Os serviços fornecidos pelo sistema silvipastoris são: sombra para o gado, melhoria na ciclagem de nutrientes, proteção de nascentes, fixação de nitrogênio e diminuição da erosão do solo (OLIVEIRA et al., 2003). Sendo assim, Figura 7 contempla os corredores propostos, que apresentaram-se como viáveis para sua implantação. 


\section{Corredores Ecológicos Viáveis}

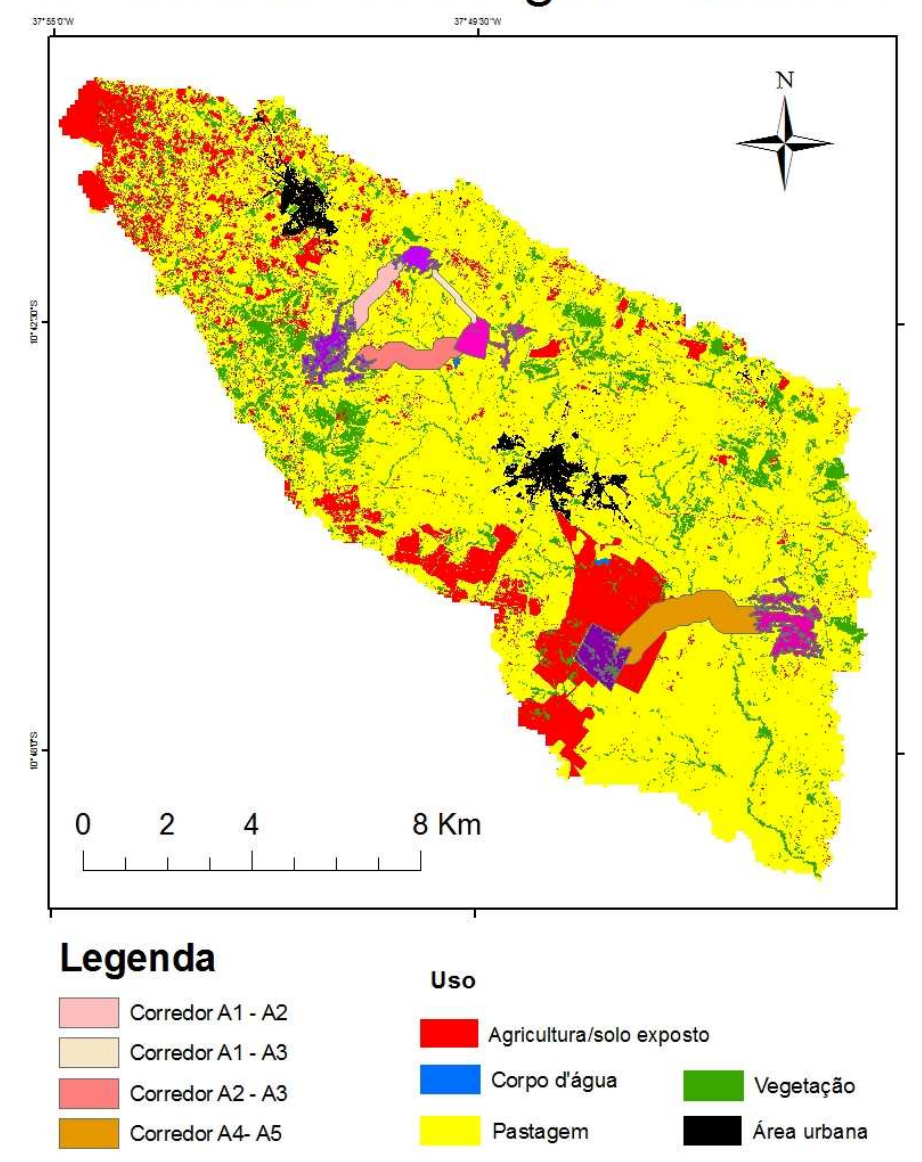

FIGURA 7. Corredores ecológicos viáveis.

\section{CONCLUSÃO}

Dos corredores propostos, os que se apresentaram como mais significativos para serem implantados foram os corredores A1-A2, A2-A3, A1-A3 e A4-A5. Sendo que, na implantação do corredor que liga as áreas 4 e 5 propõe-se que seja utilizado o sistema SAF, uma vez que o corredor atravessa uma área agrícola e esse sistema concilia a preservação da natureza e a prestação de serviços ambientais com a produção vegetal.

$\mathrm{Na}$ área delimitada pelos corredores A1-A2, A2-A3 e A1-A3, a construção de uma estrada ecológica torna-se fundamental, uma vez que vai atravessar uma área agrícola e de pastagem. Vale salientar, que a existência de uma aglomeração urbana próxima aos fragmentos vegetados e aos corredores propostos eleva a necessidade de uma fiscalização para diminuir o impacto de possíveis atividades antrópicas nessa região.

\section{REFERÊNCIAS}

ANDERSON, A. B.; JENKINS, C.N. Review of Applying Nature's Design: Corridors as a Strategy for Biodiversity Conservation. Great Plains Research: A Journal of Natural and Social Sciences, v. 17, n. 1, 2007. 
AYRES, J. M.; FONSECA, G. A. D. da; RYLANDS, A. B.; QUEIROZ, H. L.; PINTO, L. P.; MASTERSON, D.; CAVALCANTI, R. B. Os Corredores Ecológicos das Florestas Tropicais do Brasil. SCM. 2005, 256 p.

BRIENZA, S.; MANESCHY, R. Q.; MOURÃO, M.; GAZEL, A. B.; YARED, J. A. G.; GONÇALVES, D.; GAMA, M. B. Sistemas Agroflorestais na Amazônia Brasileira: Análise de 25 Anos de Pesquisas. Pesquisa Florestal Brasileira, v. 1, n. 60, p. 6776, 2009.

BRASIL. Ministério do Meio Ambiente. Série corredores ecológicos: 12 anos de trabalho pela conservação da biodiversidade nacional. Brasília, 40 p. 2015.

CARDOSO, J.; AQUINO, C. M. S. Mapeamento atual do uso e cobertura das terras da sub-bacia do Riacho do Roncador em Timon (MA) utilizando imagens do Google Earth. OKARA: Geografia em debate, v. 8, n. 2, p. 328-343, 2014.

CARNEIRO, B. M.; BERNINI, H.; SILVA, A. G. Perspectivas de conexão entre fragmentos florestais do Corredor Ecológico Burarama-Pacotuba-Cafundó, na Mata Atlântica do Espírito Santo, através de recomposição de Áreas de Proteção Permanente de cursos d'água. Natureza on line, v. 11, n. 1, p. 20-28, 2013.

CONSELHO NACIONAL DO MEIO AMBIENTE (CONAMA). Resolução no09, 24 de outubro de julho de 1996. Dispõe sobre corredor de vegetação entre remanescentes como área de trânsito para a fauna. (On line). Disponível em: < http://www.mma.gov.br/port/conama/res/res96/res0996.html>. (Acesso em: $02 \mathrm{dez}$ de 2015).

DEVIDE, A. C.; REBOUÇAS, A. C. Aguas doces no Brasil- capital Ecológico, uso e conservação, Editora Escrituras. 2000, 115 p.

FERRARI, J. L.; SILVA, S. D. da; SANTOS, A. R.; GARCIA, R. F. Análise morfométrica da sub-bacia hidrográfica do córrego Horizonte, Alegre, ES. Revista Brasileira de Ciências Agrárias, v. 8, n. 2, p.181-188, 2013.

LOUZADA, F. L. R. O.; OLIVEIRA, L. R.; SANTOS A. R.; SILVA, A. G.; OLIVEIRA, O. M.; OLIVEIRA, G. G.; SOARES, V. P.; PELUZIO, J. B. E. Proposta de corredores ecológicos para interligação de parques estaduais utilizando geotecnologia, Espirito Santo (ES)-Brasil. Revista Geográfica Venezolana, v. 53 n. 2, p. 239-254, 2012.

OLIVEIRA, T. K.; FURADO, S. C.; ANDRADE, C. M. S.; I. L. FRANKE. Sugestões para implantação de sistemas silvipastoris. Rio Branco. 2003.

PEREIRA, M. A. S; NEVES, N. A. G. de S.; FIGUEIREDO, D. F. C. Considerações sobre a fragmentação territorial e as redes de corredores ecológicos. Geografia, v. 16, n. 2, 2007.

ROCHA, C. F. D.; BERGALLO, H. G.; SLUYS M. V. Corredores ecológicos e conservação da biodiversidade: um estudo de caso na Mata Atlântica. In: ROCHA, 
C. F. D.; BERGALLO, H. G.; SLUYS, M. V.; ALVES, M. A. S. (Org). Biologia da Conservação: Essências. São Carlos: Rima, 2006.

SEOANE, C. E. S.; DIAZ, V. S.; SANTOS, T. L.; FROUFE, L. C. M. Corredores ecológicos como ferramenta para a desfragmentação de florestas tropicais. Pesquisa Florestal Brasileira, v. 30. n. 6, p. 207-216.

SAATY, T. L. A. Scaling method for priorities in hierarchical structures. Journal of mathematical psychology, v. 15, n. 12, p. 234-281, 1977.

TEWKSBURY, J. J.; LEVEY, D.J.; HADDAD, N.M.; SARGENT, S.; ORROCK, J. L.; WELDON, A.; DANIELSON, B. J.; BRINKERHOFF, J.; DAMSCHEN, E. I.; TOWNSEND, P. Corridors Affect Plants, Animals, and Their Interactions in Fragmented Landscapes. Ecology, v. 99, n. 20, p.1223-1226, 2002. 